colon was exposed, opened, and a Paul's tube was tied in. The patient made no improvement and died the same evening.

At the necropsy the large intestine was found to be distended as far down as the brim of the pelvis, at which point a gall-stone of the size and shape of a hen's egg was found impacted (see illustration). The bowel below this point was empty. Slight manipulation from without sufficed to liberate the stone. There was no surrounding peritonitis and on opening the bowel it was seen that the presence of the stone had caused no lesion of the mucous membrane. The transverse colon and the gall-bladder were found embedded in a mass of adhesions and a communication of the diameter of a florin was found between their cavities. The common bile duct was obliterated. Other calculi were found in the gallbladder.

It would appear that the fistulous communication between the gall-bladder and the transverse colon dated from the illness some four months before admission; that the escape of the stone, partial or complete, into the transverse colon was the cause of the initial symptoms of obstruction; that the liberation of the stone during the separation of adbesions was responsible for the apparent relief of the obstruction at the operation ; and that the subsequent lodging of the stone in the upper part of the sigmoid flexure rendered the obstruction again absolute.

The condition described above is one of infrequent occurrence. Thus of 53 cases of intestinal obstruction due to impacted gall-stones collected by Courvoisier, ${ }^{1}$ in only 2.4 per cent. was the obstruction in the large intestine Leichtenstern ${ }^{2}$ mentioned 32 cases and in no instance was the obstruction in the large intestine. Barnard ${ }^{3}$ recorded nine cases, in none of which was the large intestine the site of impaction. Mayo Robson ${ }^{4}$ says: "Gall-stones producing obstruction of the intestine in nearly every case enter the bowel through a gall-bladder duodenal fistula. They rarely enter through the colon; only two specimens of the latter condition were found in the London museums."

Spanish-place, W.

\section{A CASE OF LEPROSY IN A EUROPEAN.}

BY J. H. P. GRAHAM, M.R.C.S. ENG., L.R.C.P. LOND.

A YEAR ago the patient first visited Europe, when he came to England from India, where he was born 24 years ago. $\mathrm{Hi}_{\mathbf{S}}$ parents are Fnglish, his mother has lived in India since early childhood, and they are in comfortable circumstances. Three brothers and two sisters complete the family and are known to be in good health. 16 months ago the patient says he was perfectly free from disease and enjoyed good health. He was leading an active, outdoor life and had lived in several localities in India which bear a good health reputation. $\mathrm{He}$ had not been brought in any way into actual contact with those suffering from leprosy, though he had seen some few lepers. The food on which he lived was of the usual kind taken by Europeans resident in India ; as a boy abont once a week he used to eat some dried salt fish imported from Bombay.

The onset of the present illness was insidious and without prodromata, such as headache, nausea, \&c.; this is usual though not without exception. Patches of a dull violet colour were noticed first on the forehead; the patches were discrete and varied in size from that of a sixpenny-piece to that of a penny-piece; there was some diminished feeling in the skin thus affected but not marked anæsthesia. It is said that this erythematous eruption was not complicated by bullæ or pemphigus as sometimes happens. The erythema was gradually replaced by the appearance of flat nodular growths, which have somewhat subsided, on the forehead, a not unusual circumstance, but they are very marked on the nose, particularly on the alæ, on the lips, cheeks, ears, and chin. 'The resulting facies might be more appropriately called satyriasis than leontiasis, confining oneself to the description of the ancients, which cannot be bettered in the instance under review. The nasal passages

$$
\begin{aligned}
& 1 \text { Quoted by Treves in Intestinal Obstruction. } \\
& 2 \text { Ibid. } \\
& { }^{3} \text { Annals of Surgery, vol. xxxii., p. } 161 . \\
& { }^{4} \text { Diseases of Gall-bladder and Bile-ducts. }
\end{aligned}
$$

become temporarily blocked now and again, so that there is justification for believing that the mucous membrane is involved. The voice is weak and squeaky, attacks of sorethroat are common, and there is a sense of fulness about the naso-pharynx and larynx causing a good deal of hawking at times to clear the throat. The conjunctiva of both eyes is affected; it has the appearance of having had liquid fat or vaseline injected beneath it and there are one or two small punctiform hromorrhages in each. Vision is not as acute as it was before the commencement of the illness but there is no sign of keratitis which has been noted not infrequently in previous cases. Glandular enlargement is not detected, neither is there at present any sign of ulceration, but probably these usual accompaniments will eventually supervene. The eyebrows are devoid of hair, also the eyelids, upper lip, chin, and cheeks; the loss of hair on these parts began with the onset of the illness and is in accord with the natural sequence of events. Formerly the skin of the body was thin and fair; lately it bas become darker, a somewhat dull cream colour, and thickened. Perspiration appears to be not diminished, neither is it increased, but the patient says that he is more sensitive to cold than he used to be. The skin of the external genital organs is unaffected and the hair of the scalp does not appear to be falling, though the patient believes that it is getting thinner. Some pigmented areas of skin exist on both forearms; they are discrete and the cutaneous sensibility is slightly diminished. The extensor aspect and radial side of the forearms are the parts implicated. The skin of the hands is thick and thrown into rugæ, the finger ends are somewhat clubbed, and the nails are thick and brittle, but there does not appear to be any enlargement of the hand bones.

About three months ago after a long bicycle ride the patient experienced a good deal of tingling along the front and inner aspect of both thighs. Very shortly afterwards a dull violet patch appeared on the inner aspect of the left thigh above the adductor tubercle. The patch is three inches in diameter. Now the inner aspects of both thighs are discoloured and becoming covered with pigmented spots. There are also diminished cutaneous sensibility and loss of hair. The feet are unaffected. Ordinary examination reveals no defect in any system but the cutaneous. The appetite is good but the patient is very slowly getting thinner and he complains of increasing weakness.

Leprosy was identified in the earliest times but its distinction from a certain heterogeneous group of cutaneous diseases -e g., elephantiasis, leucodermia, \&c.-was not always clearly recognised. At the present day no such confusion exists, the anatomy, geographical distribution, and clinical course are familiar, but the cause yet remains unknown. Some apology is therefore due for bringing forward a purely clinical review of a case which departs in minor details only from the general picture of the disease. The occurrence of leprosy in persons of pure European parentage is very rare. The parents of this patient are pure-bred English ; certainly his mother had lived in India since early childhood and he himself was born and brought up in the country. Contagion and heredity are looked upon with doubt as etiological factors, particularly the former, and in this instance can be discounted. A diet of dried fish is claimed as a cause. The patient certainly did as a boy have one meal per week of dried fish imported from Bombay, but the disease occurs in certain places where fish does not form an article of diet. Wallasey.

The Sociological Society.-The winter programme of this society announces that at the ordinary monthly meeting on Oct. 24th Dr. Archdall Reid will read a paper on the Biological Foundations of Society and on Dec. 18th (also an ordinary monthly meeting) M. Waxweiler (director of the Institut de Sociologie, University of Brussels) will take for his subject, "The Institut de Sociologie, its Equipment and Work." A new departure is the holding of research meetings, at which papers of interest to specialists only will be read and discussed. The following announcements of such meetings have already been made-viz, Nov. 23rd, the Study of the Individual, by J. L. Tayler, M.R.C.S. Eng., L.R.O.P. Lond.; and Dec. 19th. Biological Methods in Application to Social Problems, by M. Waxweiler. All the meetings will be held at the School of Economics and Political Science, Clare-market, W.C. Papers will also be read at the affiliated societies in the Universities of Oxford and of Manchester. 